\title{
Man changed the function of water, and the water cycle changes the climate
}

\section{Opinion}

Science has not yet revealed all the properties of water. We use water as a working fluid us a simple working fluid. Water affects not only the environment, but also the climate. As a result of human activity, the functions of the main part of the water have changed. Instead of supporting the biota by supplying its moisture, mineral and organic substances, the water comes with precipitation and returns to the atmosphere by artificial evaporation from arable land, asphalt, reservoirs, dumps. In total, people took from themselves $63 \%$ of the inhabited earth, each hectare of which contains 20 tons of underground animals. These are microbes, worms, insects, etc. insects etc., in symbiosis with a terrestrial biota $\mathrm{n}$ symbiotic relationship with plants and terrestrial.

The water cycle itself was created for millions of years. Its basis was biota - a symbiosis of vegetation and the animal world with water The balance of moisture evaporated from the land was determined by the volumes of organic fumes. The speed of evaporation or the speed of return of treated water to the atmosphere determined the comfort of the existence of all life on the planet. In accordance with this, atmospheric phenomena were established, in which the direction and force of the winds controlling the clouds, the concentration of droplets and the precipitation were strictly stabilized. The consistency of uniformly repeating cycles has created specific arid zones tropics, deserts, steppes, forests. It is known from open sources of information that the biota in the territory of the inhabited land in $63 \%$ of the arable land, the water area of artificial reservoirs, landfills, the area of cities and roads has been destroyed by mankind in the history of civilization. It is also known that every hectare of only underground living creatures contains 20 tons. All living organisms and all vegetation, each unit of which consumes water and exhales pairs of individual structure. This is known from those studies where it is stated that the person's exhalation determines the state of his health. Man is an element of biota. This is known from studies where it is stated that the exhalation of a person, as an element of a biota, determines the state of his health. Consequently, all moisture from organic has its own individual properties. Considering the territories torn away from nature in terms of their interaction with water, precipitation, you can see that these territories do not need water. After standing in a puddle of asphalt, it quickly goes back to the sky with fumes. Nature did not use the properties of water for food chains. Consequently, we destroyed the link of the natural circuit. Even larger volumes of water along the reduced chain escape into the atmosphere of water, evaporated in production technologies. For nature, all this artificial evaporations are alien and do not fit into the mechanisms of atmospheric phenomena. The water cycle has broken for thousands of years in terms of the volumes of water raised into the atmosphere, and the rate of return. A third and possibly even stronger factor is also envisaged, which requires special studies-this is the quality of evaporation, it is necessary to identify the differences between organic vapors and artificial ones.
Special Issue - 2018

Halidullin $\mathrm{O}$
Kazakh National University, Russia

Correspondence: Halidullin O, Ecology Professor,Academician of the Russian Federation LAN, Kazakh National University, Russia,Tel 87770550099,Email 7II5215@mail.ru

Received: May 30, 2018 | Published: August 01, 2018

Thus, increased volumes of artificial fumes created a failure of the mechanism of atmospheric phenomena. The forces and directions of the winds, the schedule and geography of precipitation have changed.

Populations absorb moisture, are transformed into food chains and economically exhale very individual pairs, which we call natural or organic pairs. Human intervention in the circulation of water reduces food chains, and water from asphalt and other destroyed areas evaporates immediately after precipitation. We call this evaporation artificial. Large artificial pairs are produced by industry and utilities around the world. Giant artificial evaporation creates unprecedented volumes of water in the atmosphere, which over the centuries have changed the developed mechanism of atmospheric phenomena. The cyclicity, massiveness and range of precipitation have been changed. Therefore, some areas suffer from floods, and others - from drought and fires. We give an example of only one aspect-artificial reservoirs. Several hundred new reservoirs are annually put into operation on the globe. The total area of all the reservoirs of the world is more than 600 thousand square kilometers. Many of the world's rivers-the Volga, the Dnieper, the Angara, Missouri, Colorado, Parana and others-have become water cascades. Evaporation from their waters is artificial, nature is not provided.

The purpose of this article is to draw the attention of the academic world to the creation of a group to prove the hypothesis. This will create a new unified concept of preserving life on the planet. The basis of this concept should be a comprehensive return to the nature of organic fumes and the reduction of artificial fumes. Among the measures to reduce artificial fumes, a general saving in water consumption in the everyday life of each person should be created. Complete and unconditional stop of projects and construction of reservoirs. Reconstruction of the entire agricultural sector with the introduction of shallow plowing, drip irrigation, etc.

\section{Acknowledgements}

None.

\section{Conflicts of interest}

The author declares there is no conflict of interest. 